\title{
Lessing, um espírito livre. Sobre o aforismo 103 de O Andarilho e sua Sombra
}

\author{
Ernani Chaves*
}

\begin{abstract}
Resumo: Este artigo tem como objetivo analisar o aforismo 103 de O Andarilho e sua sombra, intitulado "Lessing", com a finalidade de mostrar a confrontação de Nietzsche com o pensamento do grande ensaísta, poeta e dramaturgo, considerado o criador do teatro moderno alemão. Esta confrontação tem como ponto de partida no aforismo acima referido a questão do "estilo", o que dá a oportunidade para refletirmos acerca desta questão em Nietzsche, neste momento importante de sua obra, momento de viragem, como sabemos, em especial a partir de três outros "personagens" importantes para a discussão deste tema: Schopenhauer, Wagner e a cultura francesa.
\end{abstract}

Palavras-chave: estilo - poesia - prosa - clássico

O entusiasmo e a admiração de Nietzsche por Lessing marcam, de forma eloquente, os estudos do jovem filólogo em Leipzig. A Gersdorff, ele expressou muito cedo estes sentimentos. Com dificuldades para escrever seu trabalho sobre as fontes de Diógenes de Laertius, lembra ao amigo, em carta de 06 de abril de 1867, que se consola pensando que Lessing, Lichtenberg e Schopenhauer (denominados por ele de "as três autoridades") advertem, com frequência, "o quanto é difícil escrever bem, [pois] por natureza nenhum homem tem um bom estilo,

\footnotetext{
*Professor da Universidade Federal do Pará (UFPA), Brasil.

Correio eletrônico: erna.nic@hotmail.com
} 
Chaves, E.

deve-se trabalhar e esburacar madeira dura, para consegui-lo"I. Entretanto, em uma outra carta, escrita apenas dois anos depois, dirá a Erwin Rohde que os escritos de Wagner vão bem mais longe do que o Laokoon. Mas, se percorremos o conjunto da obra, veremos que a avaliação que Nietzsche fará de Lessing e do Laokoon, em especial, mudará bastante, tornando-se bem mais crítica. O que não quer dizer que a admiração deixará de existir. Basta lembrarmos que em Para além de bem e mal, justamente na segunda parte do livro, dedicada ao "espírito livre", Nietzsche volta a filiar Lessing à escola francesa de Bayle, Diderot e Voltaire, que tanto admirava, considerando-o uma exceção em relação aos prosadores alemães. Embora não consiga, como nenhum outro alemão, mesmo Goethe, alcançar o estilo sublime de um Maquiavel ou de um Petrônio, Lessing, um "amante do livre pensar", foge à mediocridade geral que Nietzsche atribuía a Alemanha.

O olhar crítico, por sua vez, também permanece na última notícia sobre Lessing nos Fragmentos Póstumos, datada de Novembro de 1887/Março de 1888, onde Minna von Barnhelm é considerada "un marivaudage raisonnê" ("uma afetação lógica"), julgamento que o próprio Nietzsche, certamente para acentuar a crítica, prefere assinalar em francês (Nachlass/FP 11[63], KSA 13.32). Algum tempo depois, em carta a Ferdinand Avenarius, de 20 de julho de 1888, Nietzsche afirma, confrontando-se com o livro de Victor Hehn sobre Goethe, o quanto a Alemanha deve a Heine e Lessing, acrescentando: "Isso nada diz contra Goethe (ao contrário) - mas diz algo contra a miserabilidade e a desconsideração (Undankbarkeit) dirigidas agora

1 "Esburacar madeira dura" é a tradução de "hartes Holz bohren". Lessing escreve na 46. Parte da Hamburgische Dramaturgie algo semelhante, a propósito dos desacertos dos dramaturgos franceses acerca das regras da ação dramática: "Ninguém lhes levaria isso a mal; pois não resta dúvida que assim também é possível compor excelentes peças; e o provérbio diz: perfura a tábua onde ela é mais fina" (LESSING. Werke und Briefe in zwölf Bänden, hrsg. v. Wilfried Barner. Frankfurt/M: Deutscher Klassiker Verlag, 1990, p. 46). (Em português: G. E. Lessing. De Teatro e Literatura. Tradução de J. Guinsburg, introdução e notas de Anatol Rosenfield. São Paulo: Editora Pedagógica Universitária, 1992).

298 Cad. Nietzsche, Guarulhos/Porto Seguro, v.37, n.1, p. 297-316, 2016. 
Lessing, um espírito livre. Sobre o aforismo 103 de O Andarilho ...

contra Heine e Lessing" (KSB 8.359-60).

Desse modo, toda tentativa de compreender as relações de Nietzsche com Lessing deve sempre levar em conta esta permanente tensão, que oscila entre o elogio e a crítica, o reconhecimento da contribuição intelectual de Lessing em meio a uma Alemanha dominada pelos "filisteus da cultura" e a sua impossibilidade de escapar à sedução da moral, a "Circe dos filósofos", seja nos seus estudos sobre a tragédia, seja no seu grande tratado sobre a educação ou, ainda, que afirma a "musicalidade" do seu estilo e, ao mesmo tempo, deplora sua "afetação". Um exemplo bastante claro desse procedimento se encontra no aforismo 103 do Andarilho e sua sombra que se intitula, justamente, "Lessing", que transcrevemos abaixo e, a seguir, passamos a comentar:

Lessing tem uma virtude autenticamente francesa e, em geral, é como escritor que frequentou mais assiduamente a escola dos franceses: ele sabe organizar e expor muito bem suas coisas na vitrine. Sem esta arte real, suas idéias, assim como seus objetos, teriam permanecido na sombra e sem isso o prejuízo geral seria grande. Mas, com sua arte muitos aprenderam (em especial a última geração de eruditos alemães) e inúmeros se regozijam com ela. - Entretanto, estes aprendizes não teriam tido necessidade, como tão frequentemente aconteceu, de emprestar-lhe também seu desagradável maneirismo no tom, com sua mistura de polêmica maníaca e retidão. Sobre o "lírico" Lessing há agora unanimidade: ela acabará por acontecer em relação ao dramaturgo (WS/AS 103, KSA 2.597-98).

A primeira questão que se impõe ao intérprete é se perguntar se a filiação aos franceses assinalada já no início do aforismo é positiva ou profundamente irônica, ou seja, se se trata aqui ainda do pertencimento de Lessing à escola de um Diderot e de um Voltaire ou já àquela de Marivaux e sua "afetação lógica”. A questão colocada diz respeito, antes de mais nada, ao estilo enquanto um certo arranjo, um ordenamento, uma disposição de palavras e frases, de tal modo que o seu resultado, seja um livro de crítica, um poema ou uma peça 
Chaves, E.

teatral, acabe ganhando visibilidade e alcance êxito, tal como uma mercadoria que se torna mais bela e atraente quando bem exposta numa vitrine (Schauladen).

A questão do estilo, como se sabe, é central no pensamento de Nietzsche. Nos escritos do chamado "segundo período", ela ganha uma relevância específica, pois se trata também da confrontação com Wagner e Schopenhauer. Veremos, então, em que medida a questão do estilo constitui, igualmente, um ponto de ruptura de Nietzsche com as "ilusões" juvenis.

Em um plano datado do verão de 1875, Nietzsche anunciava a "preparação de uma doutrina do estilo", juntamente com seus estudantes Baumgarten e Brenner (Nachlass/FP 8[4], KSA 8.130). O estilo de Lessing, por sua vez, sempre lhe chamou atenção, pois o considerava indissociável da profunda atração e sedução que suas idéias exerciam, como se lê neste Fragmento Póstumo do Início do Ano/Outono de 1873: "Lessing tem a força violenta, intranquila, eternamente brincalhona, visível em todos os músculos intumescidos, de um jovem tigre. A nova crença não pode remover montanhas, mas palavras (para o estilo)". (Nachlass/FP 27[35], KSA 7.597).

Ou ainda na Terceira Extemporânea, desta vez com uma ponta de ironia, ao distinguir Schopenhauer de Lessing. Se este é considerado "em relação à prosa, o autor mais sedutor dentre os alemães", é um ganho, entretanto, que Schopenhauer possa estar livre da "sutil, exageradamente móbil e - peço licença para dizê-lo - da mania (Manier) não-alemã bastante grande de Lessing" (SE/Co. Ext. III 2 , KSA 1.348) ${ }^{2}$.

Lido com atenção, o elogio ao Schopenhauer escritor parece atribuir a Lessing uma série de defeitos. O escritor, diz Nietzsche, está constantemente próximo da figura do "enganador", do "fraudador" (ein

2 Num Fragmento Póstumo posterior, referindo-se a Wagner, assim Nietzsche define "Mania": “Todas as 'Ideias' de Wagner tornam-se, imediatamente, uma sólida mania, ele torna-se tiranizado por elas. Como apenas um tal homem pode deixar-se tiranizar desse jeito?" (Nachlass/FP 27[90], KSA 8.502).

300| Cad. Nietzsche, Guarulhos/Porto Seguro, v.37, n.1, p. 297-316, 2016. 
Lessing, um espírito livre. Sobre o aforismo 103 de O Andarilho ...

Betrïger). Inconscientemente, ele imitaria o "engano social" presente em toda conversação. Conscientemente, com os meios artificiais da Retórica, incorreria na "fraude do orador". Schopenhauer, ao contrário, estabeleceria com seu leitor uma relação semelhante "a de um pai ensinando ao filho": "Trata-se de uma séria, forte, afável troca de impressões, diante de um ouvinte que ouve com amor" (SE/Co. Ext. III 2, KSA 1.347). A questão do estilo não se esgota, portanto, na estrutura interna da obra, mas persiste, para além dela, na relação estabelecida com o leitor.

Além disso, Nietzsche demarca a proximidade e $\mathrm{o}$ afastamento de Schopenhauer em relação aos escritores franceses: se, de um lado, há nele algo da "flexibilidade e da graça delicada dos bons escritores franceses", por outro, não podemos atribuir-lhe o mesmo apreço dos escritores alemães a uma espécie de culto francês da aparência. A grande exceção é Montaigne, de cuja seriedade e alegre serenidade (Heiterkeit) Schopenhauer mais se aproximava. Nesta perspectiva, permanece em aberto a questão de saber se a aproximação de Lessing com a escola francesa, tal como enunciada no Andarilho, é positiva ou não. Uma espécie de critério erigido por Nietzsche neste momento seria o grau de proximidade entre um escritor alemão e Montaigne. A referência ao autor dos Essais é aqui fundamental. Sabe-se o quanto Nietzsche admirava Montaigne, a ponto de escrever a Maria Baumgartner, em 07 de abril de 1875, que sua "idealização" de Montaigne o impedia de "compreendê-lo melhor" (KSB 5.40) ou ainda de afirmar, dez anos depois, desta feita em carta a Resa von Schirnhofer, de 11 de março de 1885, que dentre os franceses ele apreciava, sobretudo, Montaigne (KSB 7.18), opinião que repetirá, na mesma época à mãe e à irmã, em carta de 14 de março de 1885, acrescentando os nomes de Bayle e do Abbé Galiani (KSB 7.23).

$\mathrm{O}$ que fascinava Nietzsche no estilo de Montaigne? Uma resposta possível nos é dada no aforismo 176 da $1^{\text {a }}$ parte de Humano, demasiado humano, intitulado Shakespeare como moralista (MA I/HH 
Chaves, E.

I 176, KSA 2.161). Poderíamos dizer que o tema deste aforismo é o das relações entre arte e moralidade, pois se trata de perguntar como é possível refletir sobre as paixões sem recair na moralidade metafísicocristã. Considerando Montaigne como o "mestre" de Shakespeare, Nietzsche quer mostrar que a superioridade do dramaturgo inglês em relação a Schiller reside, justamente, no modo de tratar as paixões. Shakespeare segue o "estilo" de Montaigne, ou seja, a capacidade de expressar "pensamentos muito sérios", sob uma "forma afiada". A "forma afiada" não permite, poderíamos acrescentar, a "identificação" imediata com o público, tal como ocorre com Schiller. Ao contrário, ela é a expressão e o resultado da virtude da "alegre serenidade" (Heiterkeit), que aproxima, como vimos, Montaigne e Schopenhauer. Ora, as críticas ao estilo de Lessing poderiam, então, ser sintetizadas como a impossibilidade de atingir, com maior frequência, esta "forma afiada"3, impossibilidade continuada por seus jovens seguidores na Alemanha.

Mas, foi na Primeira Extemporânea, contra David Strauss, que a questão do estilo de Lessing ganhou maior relevância entre os escritos de juventude. Para Nietzsche, o livro de Strauss, objeto de seu ataque, A nova e velha crença, deve ser analisado por dois aspectos: um, o teológico; outro, que diz respeito ao escritor Strauss, ou seja, ao seu estilo. Nietzsche discute a afirmação elogiosa acerca do estilo de Strauss, uma espécie de unanimidade entre seus leitores, o que só fez aumentar o seu êxito, isto é, a de que ele seria, decididamente, um "escritor clássico" (DS/Co. Ext. I 8, KSA 1.207), seja por "sua quase dialética à la Lessing", seja pela "delicadeza, beleza e vigor de sua perspectiva estética", opinião comum tanto ao "teólogo sectário" quanto ao "ortodoxo mais escarniçado".

Nietzsche, entretanto, pretende se perguntar se, de fato, Strauss merece, como escritor, o epíteto de "clássico". Ele conduz

3 Shakespeare é o melhor leitor de Montaigne, diz Nietzsche na IV. Extemporânea (WB/Co. Ext. IV 3, KSA 1.444).

302 Cad. Nietzsche, Guarulhos/Porto Seguro, v.37, n.1, p. 297-316, 2016. 
Lessing, um espírito livre. Sobre o aforismo 103 de O Andarilho ...

seu questionamento, comparando a escritura de um livro à construção de uma casa e o escritor a um arquiteto. Assim sendo, do ponto de vista da época, um escritor clássico é aquele que escreve um livro como um edifício proporcional, cujas diversas partes formam um todo harmonioso. É como se a famosa lei das três unidades, a da ação, a do tempo e a do lugar, erroneamente atribuída a Aristóteles e que deveria orientar o dramaturgo, fosse aplicada a todos os gêneros de escrita. Ou ainda, como se o escritor clássico nada mais fosse do que a transfiguração de uma Grécia exclusivamente "apolínea", onde beleza equivale à medida e proporção. À figura do "escritor clássico", porém, Nietzsche opõe, de início, a do "erudito" que, ao contrário daquele, constrói seu livro não de acordo com um plano geométrica e matematicamente calculado, mas reunindo diversos fragmentos, que possuem certamente uma conexão, mas modificam, sobremaneira, as concepções lógicas e artísticas dominantes.

Nietzsche conclui, após examinar diversas passagens do livro de Strauss e insistindo nas metáforas arquitetônicas, que Strauss não construiu nem um templo, nem uma residência (exemplos do "clássico", na Antiguidade e na sociedade burguesa do século XIX respectivamente), mas um "jardim" em meio "a toda uma arte da jardinagem" (DS/Co. Ext. I 9, KSA 1.214-5). A descrição que Nietzsche faz de uma espécie de passeio pelo livro de Strauss, como se estivéssemos visitando uma residência da época, é de uma fina e cortante ironia. Trata-se de um passeio iniciado sob o signo das "catacumbas teológicas", com "sua escuridão e seus ornamentos enrugados e barrocos" (DS/Co. Ext. I 9, KSA 1.215). Ao final dele, chega-se ao que deveria se constituir, numa residência, na mais alta expressão do gosto refinado e da "cultura" do seu proprietário: a biblioteca e a sala de música. Na primeira, dever-se-ia encontrar, necessariamente, Lessing e Goethe, mas também Voltaire.

Como entender que, em tal companhia, Strauss permaneça, enquanto escritor, um "filisteu da cultura" e não um "clássico", como 
Chaves, E.

pensam os epígonos? A resposta está no fato de que Strauss não se decidiu tomar como modelo nem Voltaire, nem Lessing, ou mesmo ambos. Assim, ele se divide entre o "valente ímpeto dialético" de Lessing e a arte de Voltaire, sem se decidir qual desses dois rostos é o seu. Talvez porque ele não se dê conta da transmutação de Lessing, que se tornou "francês" e de Voltaire, que se tornou "alemão" e acabe confundindo "simplicidade de estilo" com "ingenuidade". Essa indecisão de Strauss torna seu estilo incompatível com a concepção de estilo que Nietzsche tinha na época, qual seja, a de uma "unidade", que estava na base de sua definição de cultura. "O filisteu da cultura" - escreve ele num póstumo do Início do Ano/Outono de 1873 - "não sabe o que é cultura - unidade do estilo" (Nachlass/ FP 27[65], KSA 7.606). Definição que a Primeira Extemporânea retomará integralmente: "Cultura é, sobretudo, unidade do estilo artístico em todas as expressões de vida de um povo" (DS/Co. Ext. I 1, KSA 1.163).

O veredicto de Nietzsche é, por isso, implacável: "Creio que se pode entender, perfeitamente, que valorizo o escritor Strauss: propriamente como um ator (Schauspieler), que representa o gênio ingênuo e o clássico" (DS/Co. Ext. I 10, KSA 1.220). A popularidade de Lessing acabaria, então, se nutrindo bastante do mal-entendido de considerá-lo um "clássico". E esse mal-entendido faria dele também o mestre dos "pequenos escritores". O que levará Nietzsche a dizer, ainda na Primeira Extemporânea, que "nenhum dos grandes escritores alemães é tão popular entre os pequenos quanto Lessing" (DS/Co. Ext. I 4, KSA 1.182-4). Afirmação igualmente problemática porque se trata, mais uma vez, de acentuar a sedução de Lessing, que atingiria, de preferência, os pequenos escritores, sedentos, por sua mediocridade, de se alimentar de um "clássico", ansiosos por um "modelo". Não por acaso, igualmente, Nietzsche descreverá, mais uma vez com desconcertante ironia, pela boca de um "amigo", que teria lhe contado um sonho, o destino reservado aos "clássicos", dentre

304 Cad. Nietzsche, Guarulhos/Porto Seguro, v.37, n.1, p. 297-316, 2016. 
Lessing, um espírito livre. Sobre o aforismo 103 de O Andarilho ...

eles Lessing: o de se transformarem em figuras fantasmagóricas num "museu de cera". Trata-se, de fato, de um pesadelo, que poderia ser considerado como o pesadelo de uma época ou de um povo em busca, custe o que custar, dos seus "clássicos" (DS/Co. Ext. I 4, KSA 1.181).

Torna-se imperioso, então, para Nietzsche, distinguir Lessing dos "clássicos" e, assim, salvá-lo das garras dos "filisteus da cultura". Como que prevendo a incorporação de Lessing ao legado alemão, ainda muito cedo, num Fragmento Póstumo do inverno de 1869-70/ Início de 1870, ele o distingue, como o "erudito ideal", de Herder, considerado o "diletante ideal" (Nachlass/FP 2 [12], KSA 7.49). Mas, é num Fragmento Póstumo de Setembro de 1876, que podemos compreender melhor a diferença em questão:

"Quase todo bom escritor escreve apenas um livro. Tudo o mais são apenas prefácios, esboços, esclarecimentos, adendos a ele; muitos bons escritores nunca escreveram seu livro, por exemplo, Lessing, cuja importância intelectual se eleva muito além dos seus escritos, das suas tentativas poéticas" (Nachlass/FP 18 [27] KSA 8.321).

Logo em seguida, no fragmento imediatamente posterior a este, Nietzsche estabelece a distinção entre o "grande escritor" (abandonando a problemática caracterização de "erudito") e o "escritor clássico", para salvaguardar Goethe:

Diferencio entre grande escritor - propriamente o criador de linguagem - sob cujo tratamento a linguagem ainda vive ou renasce - e escritores clássicos. Os últimos são chamados clássicos por serem imitáveis e por serem considerados modelos, enquanto os grandes escritores não são imitáveis. Nos escritores clássicos, a linguagem e a palavra estão mortas; o animal na concha não existe mais e então, eles enfileiram conchas e conchas. Mas em Goethe, a linguagem vive ainda (Nachlass/FP 1876, 18[28] KSA 8.321)4.

4 Homero e Shakespeare são inimitáveis, escreve Lessing na Parte 63 da Hamburgische Dramaturgie.

Cad. Nietzsche, Guarulhos/Porto Seguro, v.37, n.1, p. 297-316, 2016. 
Chaves, E.

Retomando a relação entre "clássico" e "imitação", Nietzsche está, mais uma vez, criticando a fórmula consagrada por Winckelmann, de que a imitação dos clássicos é a condição tanto da formação do artista, quanto da produção das obras-de-arte. Pode-se dizer então que Lessing não é um "clássico", ou seja, que ele não esteriliza a linguagem e as palavras, embora, muitas vezes, perca a serenidade e a sobriedade. A recusa de Nietzsche à classificação de autores como "clássicos" deve ser entendida também no contexto especificamente alemão de tentativa de afirmação de uma "literatura nacional". Esta não poderia existir se, por exemplo, um livreiro não soubesse responder à pergunta "quais são os clássicos alemães?", ou melhor, como no aforismo 125 do Andarilho, "Há 'clássicos alemães"?" (WS/ $A S$ 125, KSA 2.606). De todo modo, se tal questão é inevitável e sua resposta necessária, então Lessing deveria estar incluído entre esses "clássicos". Mas, novamente aqui, Nietzsche procede a uma inversão do conceito de "clássico" quando, referindo-se uma vez mais a Goethe, enfatiza que sua obra não pertence a uma nação, a uma língua ou a um povo determinado, rompendo com isso com toda "nacionalização" da literatura, numa clara resposta à transformação de Wagner em "alemão". A "supranacionalidade" de um escritor faria dele um "espírito livre".

Não é possível, igualmente, tomar Lessing como "modelo", pois ele nem mesmo chegou a escrever o "seu" livro. Além disso, como tornar-se "modelo" se a sua prosa não é "sistematicamente" apresentada como requer a regra e se suas principais obras se apresentam, ao contrário, como a reunião de textos fragmentários que obedece a outra lógica? O equívoco de Strauss, como também o dos "jovens eruditos" que o aforismo 103 do Andarilho aponta, está em tentar imitar um não-clássico, querendo fazer dele um clássico.

Então, vale perguntar, qual Lessing Nietzsche considera um "bom escritor"? Não é certamente ao Lessing "lírico" ou ao "dramaturgo", que os elogios de Nietzsche, quando existem, são 
Lessing, um espírito livre. Sobre o aforismo 103 de O Andarilho ...

dirigidos, mas ao Lessing historiador e crítico de arte ou ainda, como ele mesmo dirá no Nascimento da Tragédia, ao Lessing "pensador" (Cf. GT/NT 11, KSA 1.80). É preciso, portanto, distinguir entre os diversos "Lessings", dos quais Nietzsche se ocupa. À exceção de Nathan, o sábio, Nietzsche raramente se interessa pelo "dramaturgo" e, menos ainda, pelo "lírico", pois, como vimos numa citação acima, ele considera que o significado de sua obra ultrapassa, em muito, suas "tentativas poéticas". Ao sancionar o Lessing dramaturgo e lírico, como fazem os admiradores alemães, e esquecer ou deixar de lado o historiador e crítico da arte, pretende-se, em última instância, abafar a seriedade e a virulência do "pensador".

A partir daí, a comparação com Eurípedes no Nascimento da Tragédia, que já havia sido feita por Friedrich Schlegel ${ }^{5}$, pode ganhar, sem dúvida, toda a sua radicalidade. Ambos, Eurípedes e Lessing, não são poetas, mas, ao contrário, pensadores dotados de uma "extraordinária abundância de talento crítico", que "fecundou continuamente um produtivo impulso artístico secundário" (GT/ NT 11, KSA 1.80) ${ }^{6}$. Deve-se deixar de ler essas páginas em que Nietzsche responsabiliza Eurípedes, ao lado de Sócrates, pela "morte da tragédia", como uma condenação pura e simples de Eurípedes. Ao contrário, o texto também deixa o tempo todo transparecer a importância do aparecimento da figura do "homem teórico", como correlata da do artista, da qual Lessing é a mais alta encarnação. Esta importância reside no fato de que o "homem teórico" revela o impulso científico propriamente dito, em continuidade com o impulso filosófico, pois se trata, num e noutro, como Lessing afirma, de uma busca incessante do saber e não da sua apropriação. Se Sócrates constitui uma ruptura tão brusca e violenta na história do Ocidente, é porque ele nem se reconhece como dotado deste impulso, nem se

5 Cf. Nachlass/FP 1[90] e 1[94], KSA 7.38.

6 NIETZSCHE, F. Nascimento da Tragédia. Tradução, notas e posfácio de J. Guinsburg. São Paulo: Cia. das Letras, 1992, p. 77. Doravante indicado como JG.

Cad. Nietzsche, Guarulhos/Porto Seguro, v.37, n.1, p. 297-316, 2016. 
Chaves, E.

contenta em "buscar" a verdade, querendo e exigindo que, de fato, a razão penetre e se aproprie de todos os domínios. A posição de Lessing, ao contrário, prefigura aquela que os textos de Nietzsche, a partir de 1876, denomina de "probidade intelectual".

Devemos lembrar, ainda, que num póstumo do verão de 1878, podemos ler um "elogio a Eurípedes" (Euripides-Lob): "Contra nossa alegria no exagero das metáforas, das palavras raras etc." (Nachlass/ FP 30[27], KSA 8.526). Ora, em O nascimento da tragédia, já se encontra uma observação acerca do estilo de Eurípides, que prefigura o elogio deste fragmento de 1878:

Mesmo na linguagem da tragédia antiga havia para ele [Eurípides] muita coisa de ofensiva, ao menos enigmática; em especial achava haver demasiada pompa para relações muito comuns, demasiados tropos e monstruosidades para a simplicidade dos caracteres (GT/NT 11, KSA 1.81, tradução de JG).

Assim, a comparação entre Eurípides e Lessing ganha outra relevância: o pensador certamente não é um poeta, o que não quer dizer que ele deva se expressar de qualquer maneira. A linguagem do pensador - e aqui Eurípides e Montaigne estão juntos - é o contrário daquela que é "pomposa" e demasiado cheia de "imagens", para exprimir o que é mais simples e cotidiano ${ }^{7}$. Nesta perspectiva e à luz das repetidas críticas ao estilo de Lessing, pode-se dizer que, se Lessing é o exemplo do mais honrado espírito teórico, ele não alcança, do ponto de vista da forma, esta mesma plenitude. Compreende-se, portanto, que a posição de Nietzsche diante dos escritos teóricos de Lessing, quer trate-se do Laokoon, da Hamburgische Dramaturgie (que embora jamais citada, permanece como pano-de-fundo da confrontação com as teorias dos efeitos da tragédia, de Aristóteles aos contemporâneos) ou ainda do Die Erziehung des Menschengeschlechts,

7 No mesmo diapasão e na mesma época, referindo-se a Sófocles, escreve Nietzsche: “Compreendo inteiramente o desenvolvimento de Sófocles - uma vontade contrária à pompa e aos efeitos exagerados (Prunkeffect)" (Nachlass/FP 30[83], KSA 8.536).

308 Cad. Nietzsche, Guarulhos/Porto Seguro, v.37, n.1, p. 297-316, 2016. 
Lessing, um espírito livre. Sobre o aforismo 103 de O Andarilho ...

seja bem diferente daquela diante da obra lírica ou da do dramaturgo. É naquelas, principalmente, que se deve pensar a questão do estilo, da qual Nietzsche tanto se ocupou. Entretanto, pesa sobre todas essas obras um único julgamento: elas sucumbem à moral. Se Nietzsche certamente concorda com o esforço de Lessing no Laokoon, de não querer entender os gregos com as categorias contemporâneas, ele não pode aceitar que a diferença entre gregos e troianos consista no fato de que aqueles possuem uma moral e estes não. Muito menos com o sentimento de "compaixão" que a tragédia deve insuflar na alma do espectador, despertando a sua admiração pelo herói sofredor ${ }^{8}$.

Do mesmo modo, o aforismo 212 de Humano, demasiado humano, I, expressa a confrontação com a Hamburgische Dramaturgie acerca dos efeitos da tragédia9 ${ }^{9}$. Nietzsche, sem dúvida, não concorda com a solução moralizante de Lessing para o problema da catarse, até porque ele próprio procura se distanciar, desde $\mathrm{O}$ nascimento $d a$ tragédia, da teoria aristotélica, mesmo que, implicitamente, conceda um lugar especial à Poética na sua própria reflexão estética ${ }^{10}$. O

8 Cf. LESSING, G. E. Laokoon. In. Werke und Briefe in zwölf Bänden, hrsg. v. Wilfried Barner. Frankfurt/M: Deutscher Klassiker Verlag, Bd. 5/2, 1990. (Em português: Laocoonte ou sobre as fronteiras da pintura e da poesia, Introdução, tradução e notas de Márcio Seligmann-Silva. São Paulo: Iluminuras, 1998).

9 Cf. também Nachlass/FP Outubro/Dezembro de 1876, 19[99], KSA 8.354. É importante notar, a respeito, que Nietzsche emprestou da Biblioteca da Universidade da Basiléia, em 09.05.1871, o artigo de Jacob Bernays, Grundzüge der verlorenen Abhandlung des Aristoteles über die Wirkung der Tragödie, publicado em 1857 (cf. CRESCENZI, L. "Verzeichnis der von Nietzsche aus der Universitätsbibliotek in Basel entliehenen Bücher (1869-1879)"). In: Nietzsche Studien, 23, 1994, p. 407). Nietzsche, entretanto, já o conhecia da época de Leipzig (cf. Nachlass/FP 3[38], KSA 7.71; KSA 14.533). Bernays era professor de filologia em Breslau e pertencia ao círculo de Ritschl. Sua tese contradiz, em parte, a de Lessing, ao afirmar que a "purgação" é fundamentalmente "psicológica", não sendo, então, nem puramente ética, nem médica ou fisiológica. (Cf. também a respeito, BECK, P. "Préface" a Aristote, Poétique, traduit par J. Hardy. Paris: Gallimard, 1996, p. 21 ss). Um pouco antes, em 04.05.1870 e 11.02.1871, ele emprestara o livro de Paul Graf Yorck von Wartenburg, Die Katharsis des Aristoteles und der Oedipus Collones des Sophokles, Berlin, 1866 (cf. CRESCENZi, L. op. cit., p. 400 e 405). As questões colocadas por esses textos, somadas às de Lessing, são certamente retrabalhadas no capítulo 22 de Nascimento da Tragédia.

10 Entre 1869 e 1879, não há registro de empréstimos da Poética, por parte de

Cad. Nietzsche, Guarulhos/Porto Seguro, v.37, n.1, p. 297-316, 2016. 
Chaves, E.

"aristotelismo" de Lessing, no Laokoon, fará Nietzsche elogiar o afastamento de Wagner em relação ao Estagirita: "necessita-se agora mais dos escritos wagnerianos do que do Laokoon, de Lessing e dos escritos em prosa de Schiller", escreve ele num póstumo do Verão 1875, em texto preparatório à Extemporânea sobre Wagner, mas que não foi incorporado ao texto publicado (Nachlass/FP 11[32], KSA 8.222). Ainda neste mesmo fragmento, Nietzsche dirá que não há em Wagner "nenhuma boba canonização e elogio a Aristóteles, como até mesmo em Lessing". Acerca do Die Erziehung des Menschengeschlechts, por sua vez, escreve, num póstumo do fim de 1876/Verão 1877, que Lessing permanece preso às representações metafísicas, na medida em que ele ainda pensa que "um Deus tomou nas mãos a educação da humanidade e que nós não podemos compreender completamente seus caminhos" (Nachlass/FP 23[94], KSA 8.436) ${ }^{11}$, para perguntar, um pouco depois, no Fim de 1880, “Quem ainda suporta o tanto precoce quanto pretensioso Erziehung des Menschengeschlechts, de Lessing!" (Nachlass/FP 7[136], KSA 9.345).

$\mathrm{O}$ último elo desta cadeia, não poderia ser outro: trata-se de Wagner. No mesmo fragmento póstumo há pouco citado, quando elogiando o distanciamento de Wagner em relação a Aristóteles, Nietzsche critica Lessing, encontramos, igualmente, o elogio do

Nietzsche, na Biblioteca Universitária da Basiléia, embora haja referências a ela no Nascimento da Tragédia. Ao contrário, a Política (edição apenas do primeiro, segundo e terceiro livros, traduzidos por Bernays), publicada em Berlim, 1872, foi emprestada duas vezes (em 22.1.1874 e 13.04.1874), a edição completa, organizada por F. Susemihl, publicada em Leipzig, 1872, também duas vezes, em 09.01.1874 e 13.04.1874. A Retórica (Ars rhetorica, hrsg. v. L. Spengel, 2 Bde., Leipzig, 1867), duas vezes, em 09.01.1874 e 13.04.1874 (cf. Crescenzi, L., op. cit.). Acrescentese ainda que o tema da disciplina "História da Literatura Grega", no semestre de inverno 1874/75 e no semestre de verão 1875, foi a Retórica (KSA 15.60 e 63). Mas Nietzsche possuía uma edição das obras completas de Aristóteles.

11 Sobre Nietzsche e esta obra específica de Lessing, cf. KAUFMANN, W. Nietzsche. PhilosophPsychologe-Antichrist, Aus dem Amerikanischen übersetzt von Jörg Salaquarda. Darmstadt: Wissenschaftliche Buchgesellschaft, 1988, 174 ss.

$310 \mid$ Cad. Nietzsche, Guarulhos/Porto Seguro, v.37, n.1, p. 297-316, 2016. 
Lessing, um espírito livre. Sobre o aforismo 103 de O Andarilho ...

estilo de Wagner. Estamos no verão de 1875, é bom não esquecer, em plena redação da Quarta Extemporânea. Referindo-se aos escritos em prosa de Wagner, Nietzsche afirma que eles foram escritos para serem falados (em Sprechstil) e não para serem lidos (em Schreibstil), o que lhes imprime um ritmo que interrompe "a paixão arrebatadora" (die fortreissende Leidenschaft), "que rompe os períodos artificiais, pesados e extremamente inchados com palavras justapostas". Escapando dessas armadilhas, em especial no Beethoven, a prosa de Wagner torna-se "a mais bela" entre os alemães (Nachlass/FP 11[32], KSA 8.221). Sem mencionar o Beethoven e com algumas modificações pouco significativas, o elogio se mantém no texto publicado da Quarta Extemporânea (Cf. WB/Co. Ext. IV 10, KSA 1.502).

Três anos depois, entretanto, a avaliação do estilo de Wagner já está bastante modificada, tal como alguns fragmentos do Verão de 1878 o mostram:

Espanto, até que grau eu próprio pude ter prazer com o estilo de Wagner, que é tão descuidado, que um tal artista não é digno dele. Estilo de Wagner. Falar banalidades em demasia sobre os mais importantes objetos, sem um conhecimento suficiente, tornou-lhe tão impreciso quanto incompreensível: daí a ambição, que o faz igual aos folhetinistas engraçados - e, finalmente, a arrogância (Anmassung), que se acasalou, com prazer, com o descuido: "veja, tudo está ótimo" (Nachlass/FP 30[91], KSA 8.538).

A crítica se estende, como não poderia deixar de ser, ao estilo "musical", do que Nietzsche se aproveita para fazer uma autocrítica em relação ao Nascimento da Tragédia: "Comparar O nascimento da tragédia com a sinfonia do III Ato do Tristão - obscuro e patético, tal como eu, que na época adorava me expressar tendo Wagner como modelo" (Nachlass/FP 30[101], KSA 8.540). O resultado dessas críticas, lido à luz do elogio a Montaigne e a Shakespeare, mostra o quanto o Nietzsche deste período reivindicava um estilo marcado pela "alegre serenidade" [Heiterkeit], totalmente oposto aos objetivos de Wagner: "Wagner - escreve ele - que em seus escritos queria ser 
Chaves, E.

mais admirado do que compreendido" (Nachlass/FP 30[115], KSA 8.543). Este desejo de fama e glória está intimamente ligado ao "efeito narcótico ou de êxtase" da arte wagneriana (Nachlass/FP 30[122], KSA 8.544), para o qual Nietzsche, desde então, já alertava. Ao lado da arrogância, a ambição [Ehrgeiz] de Wagner, "que é ainda maior do que o seu talento" (Nachlass/FP 30[123], KSA 8.544), auxilia, definitivamente, a corromper o seu estilo.

O que significa, então, um estilo marcado pela Heiterkeit? Significa, antes de mais nada, abandonar a fraseologia moderna, marcada pelo abuso dos sentimentos, isto é, intoxicada de romantismo com suas teorias do gênio e da inspiração. Ao contrário, deve-se cultivar uma severa disciplina, a serviço da clareza, tal como o aforismo 195, de Humano, demasiado humano enuncia, tomando os gregos como exemplo:

O exagero caracteriza os textos modernos, e mesmo quando são escritos de maneira simples, as palavras que contêm são sentidas muito excentricamente. Reflexão severa, concisão, frieza, simplicidade deliberadamente levada ao extremo, em suma, restrição do sentimento e laconismo - só isso pode ajudar. Aliás, esse modo frio de escrever e sentir é agora, por contraste, muito sedutor: e aí está um novo perigo, certamente. Pois o frio agudo é um estimulante tão bom quanto o calor elevado (MA I/HH I 195, KSA $2.165-166) .{ }^{12}$

Ou ainda, no aforismo 136 do Andarilho, intitulado, significativamente, "Razão principal da corrupção do estilo":

Querer mostrar mais sentimento por uma coisa do que se tem realmente, corrompe o estilo na linguagem e em todas as artes. Antes, toda grande arte tem a inclinação contrária: ela ama, como todo homem de moralidade superior, reter o sentimento que está a caminho e não deixá-lo ir até o fim (WS/AS 136, KSA 2.611). ${ }^{13}$

12 Humano, demasiado humano. Tradução, notas e posfácio de Paulo Cesar de Souza. São Paulo: Cia. das Letras, 2000, pp. 131-2.

312 | Cad. Nietzsche, Guarulhos/Porto Seguro, v.37, n.1, p. 297-316, 2016. 
Lessing, um espírito livre. Sobre o aforismo 103 de O Andarilho ...

O exemplo do grande estilo é aqui, o de Sófocles. Mas, como se pôde ver, é como se Montaigne e Shakespeare dessem sequência à linhagem de Sófocles. Do mesmo modo, ao distinguir entre "Estilo escrito e estilo falado", no aforismo 110 do Andarilho, que leva este nome, ele diz que a dificuldade do estilo escrito está no fato de que "ele quer com muito pouco se fazer entender do mesmo modo que este [o estilo falado]" (WS/AS 110, KSA 2.600). Em relação à Alemanha, ao contrário, resta apenas a severa crítica e a constatação de que os alemães só conhecem a "improvisação". Assim, ele escreve no aforismo 95 do Andarilho:

Nenhum dos povos civilizados atuais tem uma prosa tão ruim como o alemão, e quando os espirituosos e mimados franceses dizem: não há prosa alemã, - não se deve ficar realmente zangado, pois se trata de uma gentileza maior do que a que merecemos. Quando se procura os motivos, então se chega, enfim, a um resultado raro, o de que o alemão conhece apenas a prosa improvisada e não concebe nenhuma outra (WS/AS 95, KSA 2.595).

A “improvisação", assim como o excesso de sentimentalidade, obscurece o espírito e conduz o escritor ou o poeta ao exagero de metáforas e imagens. As grandes emoções, as emoções luminosas, só poderiam ser traduzidas com sinceridade, através de um estilo caracterizado pela Heiterkeit. Esse estilo é aquele que Nietzsche, no aforismo 214 do Andarilho, "Livros europeus", credita aos franceses:

Ao ler Montaigne, La Rochefoucauld, La Bruyère, Fontenelle (sobretudo os Dialogues des morts), Vauvenargues, Chamfort, se está mais próximo da Antiguidade do que não importa qual grupo de seis autores de outras nações [...] Seus livros se elevam além das mudanças de gosto nacionais e das colorações filosóficas, nas quais agora todo livro costumeiramente reluz e deve reluzir, para tornar-se conhecido: eles contêm mais pensamentos efetivos do que todos os livros dos filósofos alemães conjuntamente (WS/ AS 214, KSA 2.646-647).

13 Esta mesma crítica da "sentimentalidade" encontra-se no aforismo 168 do Andarilho, "Sentimentalidade na música", que se dirige, antes de tudo, contra Wagner. 
Chaves, E.

O aforismo sobre Lessing só pode, então, ser compreendido se lançado em meio a esta teia de aforismos e reflexões. Afinal, de qual escola francesa ele fala, aquela que Lessing frequentou? Da de Voltaire e Diderot, da de Maurivaux ou ainda, desta última, a de Montaigne e dos "moralistas"? Podemos dizer que, talvez, Lessing tenha frequentado as três: dos primeiros, ele tem o gosto pela polêmica e, por conseguinte, por um tom polêmico, que acelera o ritmo e abusa das imagens fortes e contundentes. De Marivaux, o que haveria de mais negativo: a superficialidade e a "afetação lógica". E de Montaigne e dos "moralistas", a medida certa, a concisão e a sobriedade. Esta "mistura", semelhante àquela que Nietzsche atribuía a David Strauss, é a responsável pelas diferentes avaliações que ele faz do estilo de Lessing. Acrescente-se, ainda, que o "faro comercial" de Lessing, sua disposição para ornamentar vitrines e torná-las atraentes talvez tenha mais a ver com outra escola francesa: a de Corneille e Racine, que o próprio Lessing tanto criticara! Tudo isso torna suspeita, aos olhos de Nietzsche, a apologia a Lessing e a imitação rasteira dos epígonos. Mais ainda: a unanimidade em torno dele é ainda mais suspeita, pois a valorização do Lessing lírico e dramaturgo coloca à margem o Lessing que, do ponto de vista de Nietzsche, naquele momento, realmente importa: o historiador, o crítico, o pensador.

Mas a grande virtude de Lessing não está no seu estilo, muito menos na sua obra, mas na sua distância em relação à Alemanha, um desdém compartilhado pelo próprio Nietzsche: distância em relação ao nacionalismo e ao sentimentalismo que marcavam a cultura filisteia. A isso, Nietzsche chamará, em Além do Bem e do Mal, a natureza de "ator" [Schauspieler], de Lessing. Assim sendo, é o "ator" [Schauspieler] e não o escritor que, por fim, orna e enfeita a vitrine [Schauladen]. Esse jogo com as aparências [Schau], que embaralha não só as distinções claras e distintas entre verdade e ilusão, mas também entre as fronteiras nacionais, caracteriza, no

314|Cad. Nietzsche, Guarulhos/Porto Seguro, v.37, n.1, p. 297-316, 2016. 
livro de 1886, o "espírito livre". Parece que o Lessing Schauspieler ${ }^{14}$ triunfa, aos olhos de Nietzsche, sobre o Lessing escritor, crítico, poeta e dramaturgo. Mas isto já é assunto para uma outra conversa!

\begin{abstract}
This article aims to analyze the aphorism 103 of The wanderer and his shadow, entitled "Lessing", in order to show the confrontation of Nietzsche with the thought of the great essayist, poet and playwright, considered the creator of modern German theater. This confrontation has as its starting point at the aphorism referred above the question of "style", which gives the opportunity to reflect about this question in Nietzsche, in this important moment of his work, turning point, as we know, especially from three other important "characters" to the discussion of this subject: Schopenhauer, Wagner and the French culture.
\end{abstract}

Keywords: style - poetry - prose - classic.

\title{
Referências bibliográficas
}

BECK, P. "Préface" a Aristote, Poétique. Traduit par J. Hardy. Paris : Gallimard, 1996.

CRESCENZI, L. "Verzeichnis der von Nietzsche aus der Universitätsbibliotek in Basel entliehenen Bücher (1869-1879)". In: Nietzsche Studien, 23, 1994, p. $388-442$.

CAMPIONI, Giuliano, BARBERA, Sandro. Il Gênio Tiranno. Ragione e domínio nell'ideologia dell'Ottocento: Wagner, Nietzsche, Renan. Milão: Franco Angeli Editore, 1982.

"Wagner 'Histrio"”. In: Sulla Strada di Nietzsche. Pisa: ETS Editrice, 1993.

14. Sobre a questão do "ator" em Nietzsche, que demandaria outra investigação, cf. BARBERA, Sandro e CAMPIONI, Giuliano. Il Gênio Tiranno. Ragione e domínio nell'ideologia dell'Ottocento: Wagner, Nietzsche, Renan. Milão: Franco Angeli Editore, 1982 e CAMPIONI, Giulian. Wagner 'Histrio', in Sulla Strada di Nietzsche. Pisa: ETS Editrice, 1993.

Cad. Nietzsche, Guarulhos/Porto Seguro, v.37, n.1, p. 297-316, 2016. 
Chaves, E.

KAUFMANN, W. Nietzsche. Philosoph-Psychologe-Antichrist. Aus dem Amerikanischen übersetzt von Jörg Salaquarda. Darmstadt: Wissenschaftliche Buchgesellschaft, 1988.

LESSING, G. E. Werke und Briefe in zwölf Bänden. Hrsg. v. Wilfried Barner. Frankfurt/M: Deutscher Klassiker Verlag, 1990.

. De Teatro e Literatura. Tradução de J. Guinsburg, introdução e notas de Anatol Rosenfield. São Paulo: Editora Pedagógica Universitária, 1992.

. Laocoonte ou sobre as fronteiras da pintura e da poesia. Introdução, tradução e notas de Márcio Seligmann-Silva. São Paulo: Iluminuras, 1998.

NIETZSCHE, F. Kritische Studienausgabe (KSA). Hrsg. v. Giorgio Colli u. Mazzino Montinari. Berlin/München: Walter de Gruyter/DTV, 1982.

. Kritische Sämtliche Briefe (KSB). Hrsg. v. Giorgio Colli u. Mazzino Montinari. Berlin/München: Walter de Gruyter/DTV, 1984.

. O nascimento da tragédia. Tradução, notas e posfácio de J. Guinsburg, São Paulo: Cia. das Letras, 1992.

. Humano, demasiado humano. Tradução, notas e posfácio de Paulo Cesar de Souza. São Paulo: Cia. das Letras, 2000.

Artigo recebido para publicação em 13/08/2015.

Artigo aceito para publicação em 17/11/2015.

316 | Cad. Nietzsche, Guarulhos/Porto Seguro, v.37, n.1, p. 297-316, 2016. 